\title{
PEMANFATAN DAUN TEBU KERING (DADHOK) DENGAN PENAMBAHANBLOTONG DAN AKTIVATOR EM4 UNTUK PEMBUATAN KOMPOSDI KECAMATAN KREMBUNG KABUPATEN SIDOARJO TAHUN 2015
}

Fathwa Rakhmawati Kirana, Imam Thohari, Khambali

\begin{abstract}
Dry sugarcane leaves (dadhok) are garbages of sugar cane harvest that have not been managed properly. One of the alternatives to reduce pollution generated is to use it as compost. This study aims to determine content of dry sugarcane leaves as compost with the addition of blotong and EM4 activator.

This research uses experimental design with Pre-Post Test Only Design. There were four experiments conducted within the study: $1^{\text {st }}$ experiment was dry sugarcane leaves (control), $2^{\text {nd }}$ experiment was dry sugarcane leaves + EM4 activator, $3^{\text {rd }}$ experiment was dry sugar cane leaves + blotong, $4^{\text {th }}$ experiment was dry sugar cane leaves + EM4 activator + blotong. Data was collection by measurement and laboratory testing. Data was then analyzed descriptively by referring to the Regulation of the Minister of Agriculture numbers 70 / Permentan / SR.140 / 10/2011 and SNI 197030-2004.

Result shows that of the four experiments conducted, $\mathrm{C} / \mathrm{N}$ ratio of compost that met the requirement was the $2^{\text {nd }}, 3^{\text {rd }}$, and $4^{\text {th }}$ experiment but only the $3^{\text {rd }}$ and the $4^{\text {th }}$ experiments fulfilled ripe compost requirement (color, texture, smell). Compost of $2^{\text {nd }}$ experiment was not perfectly ripe for EM4 only reduce the value of $\mathrm{C} / \mathrm{N}$ ratio but it cannot degrade the material. On experiment 1 , $\mathrm{C} / \mathrm{N}$ ratio and compost ripeness did not meet the requirement. Macronutrients of all experiments did not meet the requirement. This was because the raw material had low macronutrients.

Findings conclude that only the $3^{\text {rd }}$ and the $4^{\text {th }}$ experiments meet the requirement of Permentan Regulation number 70 / Permentan / SR.140 / 10/2011 and SNI 19-7030-200. Experiment 1 and 2 were not qualified. Findings suggest sugar mills to distribute the abundant waste of blotong to farmers that it can be used with dry sugarcane leaves as compost. For community who posses sugar cane plantations, sugarcane leaves can be used as compost that they can use it to increase their income.
\end{abstract}

\section{Keywords : Dry Sugarcane Leaves, Blotong, EM4 activator, Compost}

\section{PENDAHULUAN \\ Latar Belakang}

Masyarakat umumnya melakukan pengolahan sampah yang mudah dan instansupaya tidak menimbulkan bau yaitu dengan cara membakarnya. Hal ini akan mengakibatkan polusi atau pencemaran udara. Proses pembakaran sampah walaupun skalanya kecil sangat berperan dalam menambah jumlah zat pencemar di udara, terutama debu dan HC. (Bahar, 1986).

Di wilayah Kecamatan Krembung Kabupaten Sidoarjo tepatnya di desa Balonggarut, sebagian besar wilayahnya terdapat sawah tebu.Tebu (Saccharum officinarum L.) menghasilkan limbah sejak masa tanam hingga pemanenan berupa daun tebu kering yang disebut dadhok yang belum begitu diperhatikan pengolahannya. Penanganan sampah tersebut hanya dibuang dan dibakar, tanpa dimanfaatkan kembali. Pada kegiatan pembakaran tersebut dapat mengakibatkan polusi udara disekitar pemukiman dan jalan raya. Hal ini dapat merugikan bagi kesehatan masyarakat, mengingat udara merupakan faktor terpenting bagi kehidupan manusia. Daun tebu kering/ dadhok biasanya tidak dikembalikan ke dalam tanah, karena kandungan haranya yang rendah dan $\mathrm{C} / \mathrm{N}$ rasionya yang tinggi, sehingga mengalami pelapukan secara alami yang lambat, padahal limbah tersebut dapat dimanfaatkan untuk peningkatan kesuburan tanah dan memiliki nilai ekonomis (Misran, 2005 dalam Nugraha, 2012).

Penelitian sebelumnya menyatakan bahwa daun tebu kering dapat dimanfaatkan untuk peningkatan kesuburan tanah, karena itu peneliti ingin memanfaatkannya menjadi kompos. Namun dari hasil uji laboratorium Badan Penelitian dan Konsultasi Industri (BPKI) diketahui bahwa $\mathrm{C} / \mathrm{N}$ rasio daun tebu kering tinggi yaitu 60,29, hal ini akan membutuhkan waktu yang lama dalam proses pengomposan.Oleh karena itu dibutuhkan penambahan bahan yang mempunyai $\mathrm{C} / \mathrm{N}$ rasio rendah supaya $\mathrm{C} / \mathrm{N}$ 
rasio daun tebu kering dapat turun.Bahan yang digunakan yaitu blotong.Blotong biasanya digunakan sebagai bahan campuran pada pembuatan kompos. Selain itu blotong memiliki $\mathrm{C} / \mathrm{N}$ rasio yang rendah yaitu 26,93 (Ismayana et.all, 2012).

Dari penelitian terdahulu penulis ingin memanfaatkan daun tebu kering sebagai kompos dengan penambahan bahan yang mempunyai $\mathrm{C} / \mathrm{N}$ rasio rendah yaitu blotong.

Tujuan

Mengetahui manfaat dan kandungan daun tebu kering sebagai kompos dengan penambahan blotong dan aktivator EM4

\section{METODE PENELITIAN}

\section{Jenis Penelitian}

Jenis penelitian ini yaitu eksperimental dengan desain One Group Pre-Post Test Only Design.

Alat, Bahan dan Prosedur Penelitian

1. Alat dengan bantalan sekam atas dan bawah, kardus.
a. Keranjang takakura dilengkapi
b. Penyemprot air.
c. Gunting/ pemotong lain.
d. Timbangan.
e. Ember.
f. Gelas ukur.
g. Indikator $\mathrm{pH}$.
h. Termometer.
i. Hygrometer.
j. Alat Tulis.

2. Bahan
a. Sampah daun tebu kering/ dadhok.
b. Blotong.
c. Aktivator (EM4).
d. Air.

3. Prosedur Penelitian
a. Percobaan 1 daun tebu kering (kontrol) sebanyak 0,25 kg.
b. Percobaan 2 daun tebu kering 0,25 $\mathrm{kg}$ ditambah 0,25 ml EM4 yang

diencerkan kedalam $25 \mathrm{ml}$ air.

c. Percobaan 3 daun tebu kering 0,25 $\mathrm{kg}$ diatmbah dengan blotong $6 \mathrm{~kg}$.

d. Percobaan 4 daun tebu kering 0,25 $\mathrm{kg}$ ditambah blotong $6 \mathrm{~kg}$ ditambah lagi EM4 $6,25 \mathrm{~kg}$ yang diencerkan dalam $625 \mathrm{ml}$ air.

e. Setelah semua bahan masuk ke dalam Takakura dilakukan pengukuran (suhu, kelembaban, pH) dan pemantauan fisik (warna, tekstur, bau) selama 3 minggu. Dari hasil tersebut dapat diketahui percobaan mana yang akan lebih cepat selesai.

f. Setelah kompos jadi ditandai dengan warna kehitaman, tenktur tanah, dan bau yang seperti tanah, dilakukan pemeriksaan $\mathrm{C} / \mathrm{N}$ rasio dan unsur hara di laboratorium.

g. Kemudian hasil tersebut disesuaikan dengan berpedoman pada Permentan no.70 tahun 2011 dan SNI 19-7030-2004.

\section{Pengumpulan Data}

Dilaksanakan dengan cara pengukuran berat bahan, suhu, kelembaban, dan pH kompos menggunakan alat timbangan, termometer, hygrometer, dan indikator $\mathrm{pH}$. Pemantauan warna, tekstur, dan bau kompos menggunakan istrumen penilaian/ tabel pemantauan.Uji laboratorium kandungan $\mathrm{C} / \mathrm{N}$ rasio dan unsur hara makro $(\mathrm{N}, \mathrm{P}, \mathrm{K})$ kompos pada laboratorium.

Analisis Data

Data yang diperoleh selanjutnya dianalisa dengan cara deskriptif dengan berpedoman Peraturan Menteri Pertanian Nomor 70/Permentan/ SR.140/10/2011 tentang Pupuk Organik, Pupuk Hayati, dan Pembenah Tanah dan SNI 19-7030-2004 tentang Spesifikasi Sampah Organik Sebagai Kompos. 
haSil PENELITIAN DAN PEMBAHASAN

1. Pengukuran Kandungan $\mathrm{C} / \mathrm{N}$ Rasio (Bahan Baku Daun Tebu Kering) dan Bahan Blotong

Tabel 1.

Pengukuran C/N Rasio (Bahan Baku Daun Tebu Kering) Dan Blotong

\begin{tabular}{|l|c|}
\hline \multicolumn{1}{|c|}{ Bahan } & C/N Rasio \\
\hline Daun Tebu Kering & 60,29 \\
\hline Blotong & 28,78 \\
\hline
\end{tabular}

Sumber : Data Primer

Berdasarkan Tabel 1. bahwa kandungan $\mathrm{C} / \mathrm{N}$ rasio bahan daun tebu kering tinggi yaitu sebesar 60,29 . Hal tersebut tidak memenuhi syarat $\mathrm{C} / \mathrm{N}$ rasio sebagai bahan baku kompos. Menurut Sutanto (2006), Syarat C/N rasio bahanbakuyang menguntungkan proses pengomposan yaitu 25-30.Sedangkan blotong C/N rasionya memenuhi syarat yaitu 28,78 . Sehingga blotong dapat digunakan sebagai bahan campuran daun tebu kering sebagai kompos.

2. Rekapitulasi Hasil Pengukuran (Suhu, Kelembaban, pH, C/N Rasio Kompos, dan Unsur Hara Makro NPK), Hasil Pengamatan (Warna, Tekstur, dan Bau), dan Waktu Pengomposan

Tabel 2.

Rekapitulasi Hasil Pengukuran, Pemantauan, Dan Waktu Pengomposan

\begin{tabular}{|c|c|c|c|c|c|}
\hline No. & Parameter & Kompos 1 & Kompos 2 & Kompos 3 & Kompos 4 \\
\hline 1. & Suhu & $29^{\circ} \mathrm{C}$ & $30^{\circ} \mathrm{C}$ & $30^{\circ} \mathrm{C}$ & $30^{\circ} \mathrm{C}$ \\
\hline 2. & Kelembaban & $50 \%$ & $45 \%$ & $43 \%$ & $43 \%$ \\
\hline 3. & $\mathrm{pH}$ & 6 & 6 & 7 & 7 \\
\hline 4. & C/N Rasio Kompos & 44,81 & 15,4 & 18,1 & 14,8 \\
\hline 5. & Warna & Sesuai bahan & Sesuai bahan & $\begin{array}{c}\text { Hitam keabu- } \\
\text { abuan }\end{array}$ & $\begin{array}{l}\text { Hitam keabu- } \\
\text { abuan }\end{array}$ \\
\hline 6. & Tekstur & $\begin{array}{l}\text { Sesuai bahan } \\
\text { (Daun Tebu } \\
\text { Kering) }\end{array}$ & $\begin{array}{l}\text { Sesuai bahan } \\
\text { (Daun Tebu } \\
\text { Kering) }\end{array}$ & $\begin{array}{l}\text { Tanah yang } \\
\text { bercampur } \\
\text { daun tebu } \\
\text { kering }\end{array}$ & $\begin{array}{c}\text { Tanah hitam } \\
\text { dan daun tebu } \\
\text { terdegradasi }\end{array}$ \\
\hline 7. & Bau & $\begin{array}{c}\text { bau daun tebu } \\
\text { kering }\end{array}$ & $\begin{array}{l}\text { bau daun } \\
\text { tebu kering }\end{array}$ & Bau Tanah & Bau Tanah \\
\hline 8. & $\begin{array}{l}\text { Unsur Hara Makro: } \\
\text { Nitrogen } \\
\text { Phosfor } \\
\text { Kalium }\end{array}$ & $\begin{array}{l}0,37 \% \\
0,32 \% \\
0,34 \% \\
\end{array}$ & $\begin{array}{l}0,85 \% \\
0,42 \% \\
0,51 \% \\
\end{array}$ & $\begin{array}{l}0,72 \% \\
0,36 \% \\
0,44 \% \\
\end{array}$ & $\begin{array}{l}0,87 \% \\
0,36 \% \\
0,38 \% \\
\end{array}$ \\
\hline 9. & Waktu Pengomposan & $>3$ minggu & 3 minggu & 3 minggu & 2 minggu \\
\hline
\end{tabular}

Sumber : Data Primer 
Berdasarkan Permentan nomor 70/SR.140/ Permentan/SR.140/10/2011 tentang Pupuk Organik, Pupuk Hayati dan Pembenah Tanah bahwa persyaratan teknis minimal pupuk organik padat parameter $\mathrm{C} / \mathrm{N}$ rasio pupuk organik/kompos yaitu 15-25. Untuk unsur hara makro $(\mathrm{N}, \mathrm{P}, \mathrm{K})$ minimal $4 \%$. Sedangkan untuk suhu, kelembaban, $\mathrm{pH}$, warna, tekstur dan bau diatur sesuai SNI 19-7030-2004 tentang Spesifikasi Bahan Organik Sebagai Kompos. Suhu kompos sesuai dengan suhu tanah yaitu $30{ }^{\circ} \mathrm{C}$, dengan kelembaban maksimal 50\%, dan pH 6,80-7,49. Warna kompos berwarna kehitaman, dengan tekstur seperti tanah liat, dan berbau tanah.

Menurut Permentan dan SNI tersebut yang memenuhi syarat yaitu kompos 3 dan kompos 4.Kompos 3 dengan komposisi daun tebu kering+blotong, dan kompos 4 daun tebu kering+blotong+EM4. Kompos 1 dan 2 tidak memenuhi syarat. Karena Kompos 1 tidak mendapat bantuan dari bahan lain seperti EM4 dan blotong.

Menurut Nugraha, 2012 daun tebu kering memiliki $\mathrm{C} / \mathrm{N}$ rasio yang tinggi dan unsur hara rendah oleh karena itu daun tebu kering tidak dapat melakukan proses pengomposan sendiri, harus ada bahan tambahan yang membantu pengomposan supaya lebih cepat jadi.

Kompos 2 tidak memenuhi syarat dikarenakan bahan dasar kompos terlalu kering. Menurut Sutanto, 2006 bahan yang terlalu kering dapat menyebabkan proses dekomposisi lambat atau bahkan berhenti. Cara menanggulanginya harus ditambah bahan kompos segar dan diberi air.

Kandungan unsur hara pada masing-masing kompos tidak memenuhi syarat dikarenakan kandungan unsur hara yang dimiliki bahan dasar (daun tebu kering) rendah (Misran, 2005 dalam Nugraha, 2012).

Waktu pengomposan yang paling cepat dari keempat kompos yaitu kompos 4.Karena kompos 4 daun tebu kering mendapat bantuan lebih banyak daripada kompos lainnya, yaitu blotong dan EM4. Blotong mempunyai $\mathrm{C} / \mathrm{N}$ rasio rendah dengan bahan organik yang cukup banyak yaitu $14,8 \%$ (Ismayana et all., 2012).

Sedangkan EM4 berfungsi untuk mempercepat proses pengomposan dan mengurangi bau busuk yang ditimbulkan oleh kompos.

\section{KESIMPULAN}

1. $\mathrm{C} / \mathrm{N}$ rasio bahan memenuhi syarat, dari $\mathrm{C} / \mathrm{N}$ rasio daun tebu kering ditambah dengan $\mathrm{C} / \mathrm{N}$ rasio blotong mendapatkan $\mathrm{C} / \mathrm{N}$ rasio bahan campuran 30 .
2. Suhu pada proses pengomposan daun kompos 1 memenuhi syarat, kompos 2 tidak memenuhi syarat, kompos 3 memenuhi syarat, kompos 4 memenuhi syarat.

3. Kelembaban pada proses pengomposan kompos 1 memenuhi syarat, kompos 2 memenuhi syarat, kompos 3 memenuhi syarat, kompos 4 memenuhi syarat.

4. $\mathrm{pH}$ pada proses pengomposan kompos 1 tidak memenuhi syarat, kompos 2 tidak memenuhi syarat, kompos 3 memenuhi syarat, kompos 4 memenuhi syarat.

5. Kandungan $\mathrm{C} / \mathrm{N}$ rasio kompos kompos 1 tidak memenuhi syarat, kompos 2 memenuhi syarat, kompos 3 memenuhi syarat, kompos 4 memenuhi syarat.

6. Kualitas fisik warna, tekstur, dan bau kompos 1 dan 2 tidak memenuhi syarat sedang kompos 3 dan 4 memenuhi syarat

7. Waktu yang dibutuhkan dalam proses pengomposan adalah 3 minggu kecuali kompos 4 hanya perlu 2 minggu saja.

8. Kandungan unsur hara makro nitrogen, phosfor, kalium semua jenis kompos 1 s.d 4 tidak memenuhi syarat.

\section{Saran}

a. Khususnya bagi masyarakat yang mempunyai tanaman tebu, daun tebu kering dapat dimanfaatkan sebagai kompos untuk menambah penghasilan. Karena kompos tersebut bernilai ekonomis.

b. Untuk Pabrik Gula sebaiknya limbah blotong yang dihasilkan didistribusikan ke petani untuk dimanfaatkan dengan sampah daun tebu kering sebagai kompos.

\section{DAFTAR PUSTAKA}

Hadisuwito, Sukamto, 2010. Membuat Pupuk Kompos Cair. Jakarta, PT AgroMedia Pustaka. Cetakan 5.

Ismayana et all., 2012. Faktor Rasio C/N Awal dan Laju Aerasi Pada Proses Co-Composting Bagasse dan Blotong, Jurnal Teknologi Industri Pertanian. 22(3).

Misran, Erni, 2005. Industri Tebu Menuju Zero Waste Industry, Jurnal Teknologi Proses. 4(2).

Nugraha, A.W., Supriyanto, Agus, dan Ni'matuzahroh, 2012. Isolasi dan Biodegradasi Limbah Daduk oleh Kapang Selulotik dan Perkebunan Tebu. Surabaya, 
Skripsi Fakultas Sains dan Teknologi, Universitas Airlangga.

Sarudji, Didik, 2010. Kesehatan Lingkungan. Sidoarjo, Media IImu.

Soedomo, Moestikahandi, 2013. Kumpulan Karya IImiah Pencemaran Udara. Bandung, Penerbit ITB.

Peraturan Menteri Pertanian Nomor 70/Permentan/SR. 140/10/2011 Tentang Pupuk Organik, Pupuk Hayati, dan Pembenah Tanah.

Soeryoko, Hery, 2011. Kiat Pintar Memproduksi Kompos dengan Pengurai Buatan Sendiri. Yogyakarta, Lily Publisher. Cetakan 1.

Suwarto, dan Octavianty, Yuke, 2010. Budidaya Tanaman Perkebunan Unggulan. Jakarta, Penebar Swadaya. Cetakan 1.
SNI 19-7030-2004 tentang Spesifikasi Bahan Organik Sebagai Kompos.

Zulkifli, Arif, 2014. Dasar-Dasar IImu Lingkungan. Jakarta, Salemba Teknika. Cetakan 1

Notoadmojo, Soekidjo, 2010. Metodelogi Penelitian. Jakarta, PT Rineka Cipta.

Mukono., 2011. Aspek Kesehatan Pencemaran Udara. Surabaya, Pusat Penerbitan dan Percetakan Universitas Airlangga.

Sucipto, Dani Cecep, 2012. Teknologi Pengolahan Daur Ulang Sampah. Yogyakarta, Gosyen Publishing.

Mukono, H.J, 2012. Prinsip Dasar Kesehatan Lingkungan. Surabaya, Airlangga University Press.

Tim Penulis Penebar Swadaya, 2011. Penanganan dan Pengolahan Sampah. Jakarta: Penebar Swadaya.

Tosepu, Ramadhan, 2010. Kesehatan Lingkungan. Surabaya: Bintang Surabaya. 